\title{
Sadly, We only Came Second
}

\section{Dear Reader,}

There is an old saying that second place is the first loser. Although this may be a rather radical view, it very clearly describes a situation where the participants set themselves the highest standards and then fail to meet them. This was the experience recently of the German men's rowing eight who were narrowly beaten by New Zealand in the race for Olympic gold. In most other sporting disciplines, a silver medal would have been regarded as a success, but the members of this prominent rowing team had set their sights higher.

German engineers have also recently lost a race in a discipline that they specialize in: mechanical engineering. In this area, China has overtaken Germany as the world's largest exporter. And what do you do if you're a good loser? Just the same as in a sporting competition: pick yourself up, dust yourself down and start all over again. There was a good reason why German engineers were world leaders for so long. And if they are to return to the top, they must not let themselves be overshadowed or put on the back foot. Instead they must proudly stand by their products, including the combustion engine, which has been developed to an unparalleled standard in Germany. We can and must be proud of that, because combustion engines running on $\mathrm{CO}_{2}$ neutral synthetic fuels can and must make a decisive contribution to reducing emissions. I am convinced of this and the majority of engine developers are of the same opinion.

The diesel scandal caused considerable damage, and its after-effects are still very noticeable today. But now as then, the product remains a great engineering achievement. Unfortunately those involved behaved like immature teenagers who had been caught cheating, perhaps partly because they were afraid of failing to meet the necessary high standards and of being revealed as the first losers.

True sporting spirit is needed precisely when things are not going well. On the one hand, it is a time to remind yourself of your strengths and to work consistently and confidently toward your goals, while on the other, you should also be open to new approaches and to the latest developments.

I hope you enjoy this issue of MTZworldwide.

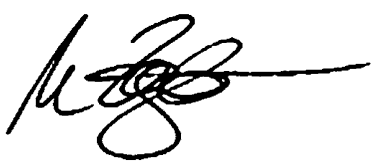

Marc Ziegler

Deputy Editor in Chief

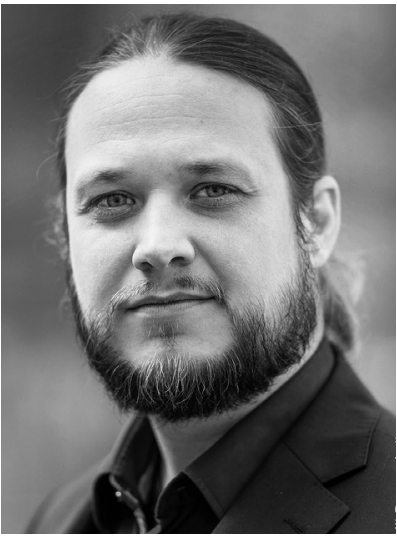

We see.

We understand. We deliver.

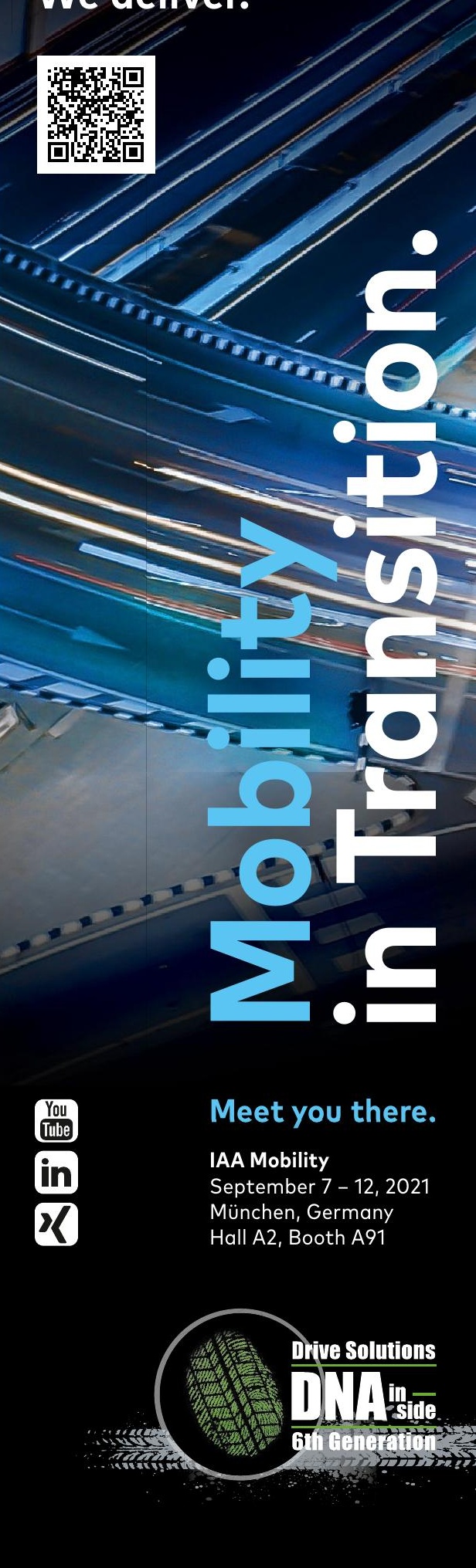

